\title{
Narrative review: craniofacial bone regeneration-where are we now?
}

\section{Hadi Khazaal, Joseph Helman^}

Department of Oral and Maxillofacial Surgery, School of Dental Medicine, Case Western Reserve University and University Hospitals, Cleveland, OH, USA

Contributions: (I) Conception and design: Both authors; (II) Administrative support: None; (III) Provision of study materials or patients: None; (IV) Collection and assembly of data: None; (V) Data analysis and interpretation: None; (VI) Manuscript writing: Both authors; (VII) Final approval of manuscript: Both authors.

Correspondence to: Joseph Helman. Department of Oral and Maxillofacial Surgery; School of Dental Medicine, Case Western Reserve University and University Hospitals, Cleveland, OH, USA. Email: hak61@case.edu.

Background and Objective: The craniofacial structures are complex and esthetically the most important component of appearance. Defects in this region lead to noticeable deformities that are physically and psychologically devastating to patients. Advances in grafting and tissue transfer techniques have improved the surgical outcomes but our ability to fully regenerate the lost or defective tissue is limited. The purpose of this narrative review is to give attention to the advances that have been made towards the development of new techniques to reconstruct craniofacial bony defects using a tissue engineering approach. The aim is to bring together up to date knowledge about biomaterials that make up an ideal scaffold; different stem cell sources and their uses; growth factors and methods of delivery to defect sites; and gene therapy techniques through different vectors.

Methods: A detailed data-based search using google scholar was performed looking for articles in English with the search including the following terms: bone regeneration, tissue engineering, craniofacial reconstruction, scaffolds, osteoinductive growth factors. The search was supplemented checking references of relevant review articles.

Key Content and Findings: Currently, research and clinical approaches to achieve craniofacial bone regeneration are attempting to shift to new techniques to avoid intensive surgeries. Considering new technology and biomaterials, techniques are aimed at targeting delivery of specific cellular components and factors that influence the growth of native bone. Currently no method investigated has been proven to fulfil all characteristics needed to replace autologous grafting as the new gold standard.

Conclusions: Currently the gold standard for craniofacial bone regeneration is still autologous grafting, but the invasiveness and surgical morbidities involved has prompted research to explore further options. This narrative review concludes that: the incorporation of computer aided designs have advanced our ability to mimic the configurations, morphologic traits and mechanical function of the native site; the recently developed techniques to obtain and process stem cells from new sources, have potentiated our ability to regenerate bone with ease; incorporation of growth factors, show promise in their regeneration ability; innovations in gene therapy and vectors have demonstrated successful bone regenerations capabilities. With advances in all aspects, we are inching closer to discovering a new gold standard.

Keywords: Bone regeneration; tissue engineering; craniofacial reconstruction

Received: 29 January 2021; Accepted: 25 January 2022; Published: 10 March 2022.

doi: $10.21037 /$ fomm-21-9

View this article at: https://dx.doi.org/10.21037/fomm-21-9

\footnotetext{
^ ORCID: 0000-0002-3854-368x.
} 


\section{Introduction}

\section{Background}

Reconstructive surgery can prove difficult in large craniofacial skeletal defects occurring from congenital conditions, trauma or cancer resections which can cause significant functional, esthetic, and psychological impairment to patients. The ability of a surgeon to repair these defects has been evolving over the years with the advent of new technology and techniques. Most studies now focus on "Critical sized defects" which are those that may never heal on their own and require repair through complex reconstructive methods (1). There is a variety of ways to reconstruct craniofacial defects.

Autologous bone has been commonly used as the gold standard for the reconstruction of these defects (2). These autologous grafts contain all the required fundamental elements that are essential for tissue engineering to be successful. A variety of autologous sites exist and have shown clinical success for many years (3). However, autologous bone is undesirable to some due to the need for a second surgical site, increased surgical cost, increased operating time, increased patient discomfort and risk for donor site complications. Also, oftentimes, the amount of available tissue is not sufficient enough to cover the defect $(4,5)$. The incorporation of free tissue transfer and microsurgical techniques have increased reconstructive options but the need for a donor site still exists and truly limits this route.

Many biomaterials have been introduced to overcome some of the limitations to autologous grafting and can be a potential alternative. These materials can be synthetic or natural and work by composing an intimate contact with the surrounding tissue. They form a matrix that establishes an environment which promotes the adhesion of cells, allows for cellular proliferation, and activates cells to differentiate all while maintaining a structurally stable complex that allows for osteoconduction. Although they are an alternative, biomaterials are not the ideal option for critically sized craniofacial defects. They have been shown to carry a greater infection risk and higher failure rates than autologous grafting (6). There is a wide variety of biomaterial available today, including: bone ceramics, demineralized bone matrix, and various other polymers.

Approaching regeneration of bone through tissue engineering has shown some potential in recent studies. This approach attempts to utilize the optimal combination of cell types, growth factors and scaffold. Tissue engineering has the benefit of eliminating second surgical sites, significantly reducing the amount of time spent in the operating room and under anesthesia, reducing the technical sensitivity of the repair, and improving the ability to replicate the original craniofacial environment required for bone regeneration. Modern tissue engineering techniques include the incorporation of growth factors into carriers, gene therapy to stimulate the production of the desired factors, and the use of stem cells to promote the repair response in the target site (7-19). The known limitation of these scaffolds is the requirement of a hermetically closed vascularized recipient site.

The goal of the review is to feature the advances in bone regeneration and its potential use in craniofacial skeletal defects. The discussion will focus on tissue engineering, gene therapy, and stem cell biology. Human clinical applications in this topic are limited to date, but as we expand our knowledge, we see the potential promise that exists in this aspect of craniofacial bone regeneration. We present the following article in accordance with the Narrative Review reporting checklist (available at https://fomm.amegroups. com/article/view/10.21037/fomm-21-9/rc).

\section{Methods}

In this review, a detailed data-based search was performed following terms: bone regeneration, tissue engineering, craniofacial reconstruction, scaffolds, osteoinductive growth factors (Table 1). The search was supplemented checking references of relevant review articles.

\section{Discussion}

\section{Tissue engineering}

Tissue engineering is an evolving field that applies a multidisciplinary approach to the construction of biologic substitutes that can re-establish original anatomic, functional, and esthetic issues from damaged or lost tissue (20). The basic concept behind tissue engineering consists of cell isolation, expansion, and reimplantation in combination with a mechanical scaffolding (21). To optimize bone regenerative potential in reconstruction of critical sized defects through the tissue engineering approach, three necessary aspects must be included in the process; an osteoconductive scaffold, osteogenic progenitor cells and osteoinductive growth factors which leads to eventual neovascularization, osteogenesis and scaffold resorption to allow for replacement with new bone to replace damaged 
Table 1 The search strategy summary

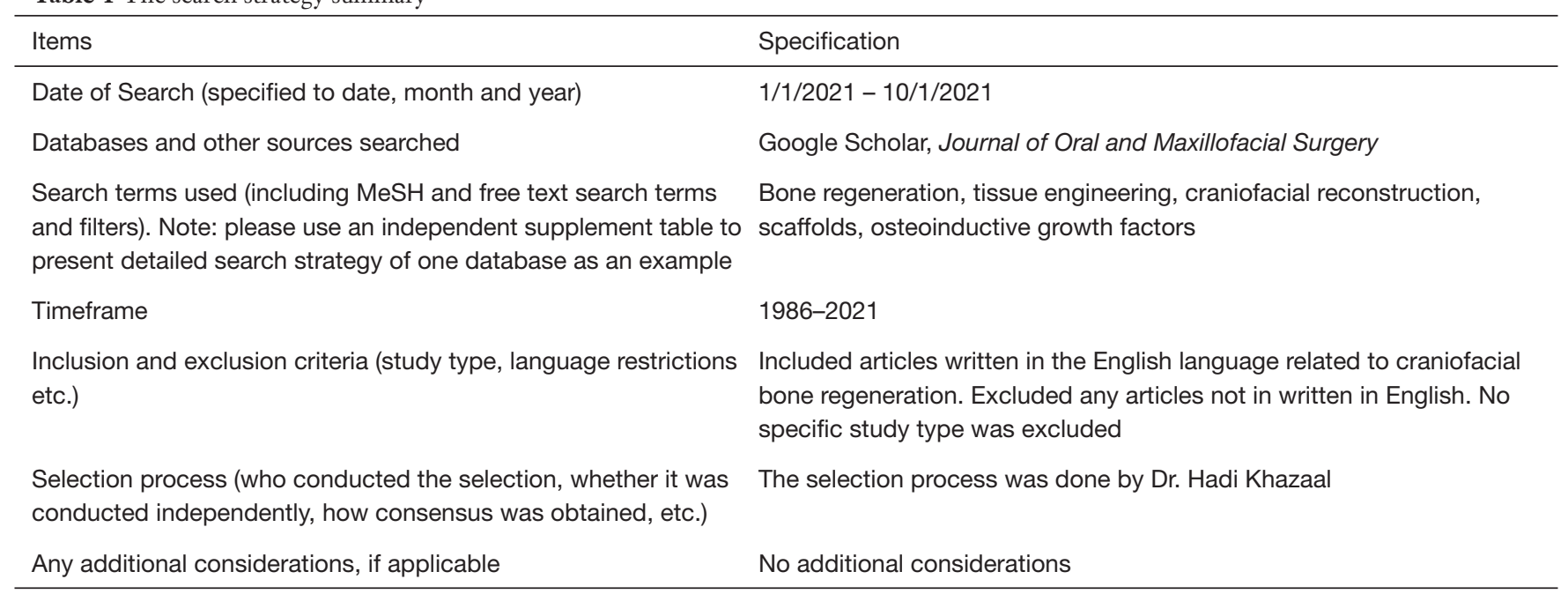

or diseased tissue. Craniofacial bone structures such as the alveolar ridge (22), the maxillary sinus (23), and the hard palate (24) have been shown in clinical studies to have successful outcomes in bone regeneration through tissue engineering.

\section{Scaffold}

In the tissue engineering model, the fundamental role of the scaffold is a structural component that acts as a carrier for cells and growth factors. It functions to stimulate the extracellular matrix (ECM), which in turn affects cellular adhesion, migration, proliferation, and differentiation (25). The perfect scaffold contender must achieve the following: The ability to carry progenitor cells needed to be delivered or assist in the recruitment of host cells via a materials osteoconductive and osteoinductive properties; to controllably deliver signaling molecules that can be released at a specific time and to a specific site via growth factor incorporation and surface alteration; the ability to stimulate tissue ingrowth and neovascularization via alterations in the scaffolds microarchitecture; the ability to accurately recreate the craniofacial skeleton to its original form through the use of Computer-Aided Design (CAD) based scaffold methods; to provide initial flexibility while preserving load bearing strength via selection of the appropriate manufacturing method; and to have the optimal material composition that will allow for timely degradation into a biocompatible byproduct that correlates with the time it takes for tissue to regenerate (26-34).
Scaffolds come in a variety of types which are split into: synthetic and natural polymers; glass and bioactive ceramics; metals; and hydrogels. There are also composite scaffolds available, which are a mixture of multiple materials (35).

Natural scaffolds have shown to have osteoconductive properties aiding in bone formation making them a good scaffold material. Collagen, chitosan, calcium alginate, hyaluronic acid and composite mixtures are part of the Natural scaffold group (36-39). But natural scaffolds lack mechanical integrity, so synthetic scaffolds with structural stability have been investigated. Synthetic polymers have the capability to assist osteoblastic differentiation and development of boney tissue. Examples of synthetic polymers are polycaprolactone (PCL), polylactic acid (PLA), co-polymer polylactic-co-glycolic acid (PLGA), polyglycolic acid (PGA), polymethyl meth-acrylate (PMMA) (40). Able to accurately imitate the structure and chemical composition of the ECM are the calcium phosphate ceramics which include ß-TCP, hydroxyapatite (HA) and biphasic calcium (35). Ceramics have promise as scaffold material due to their availability, reliability, biocompatibility, ease of sterilization, safety, and long shelf life (41). Biodegradable metals have shown the ability to imitate mechanical and structural properties of the natural skeleton, all while holding the capacity to resorb after a period of time (42). Magnesium $(\mathrm{Mg})$ and its alloys support the differentiation of progenitor cells into osteoblasts and are then degraded into hydrogen gas and magnesium hydroxide (43). Glass based scaffolds fall into two groups: glass ceramics and glass-polymer porous composites. Silicone found in glass has demonstrated the 
ability to enhance vascular growth as well as new bone formation and growth factor production in osteoblasts regulated by gene expression (35). It has been confirmed by several studies that stimulation of osteogenesis is possible through the use of scaffolds based off of silicate (44-46).

The future of biomaterials is moving towards Bio-based polymers which are produced from renewable resources like plants, algae, and bacteria that are more environmentally respectful. Many confuse the term bio-based with biodegradable, which is a term that defines the property of a material that degrades through a biologic process. The term Bio-based is not a word portraying the property of the polymer but the physical makeup of the material. These polymers eliminate the use of fossil fuels, decrease emission of carbon dioxide, and greatly benefits the environmental impact (47). The process of developing bio-based polymers includes bacterial fermentation to create the monomers from renewable resources like starch and cellulose, organic waste, and fatty acids. There are also natural bio-based polymers that include nucleic acids, proteins, and poly saccharides. The production of bio-based polymers through the use of renewable resources can be done in three ways: through micro-organisms by fermentation to produce polyhydroxyalkanoates; through polymers from agriculture resources by extraction and separation to get starch, cellulose, and alginates; and through conventional synthesis using biotechnology to get poly lactides, polybutylene succinate (PBS), and polyethylene (PE) $(47,48)$. With advances in technology and public environmental view, we are closer than ever to fully replacing conventional polymers with bio-based polymers. The reason a full transition to bio-based products has been a challenge is due to the price point and the performance compared to the conventional polymers (47).

Recent innovations in $3 \mathrm{D}$ printing technologies combined with digital imaging have provided significant advances in the production of patient specific constructs. With the use of CT imaging and custom 3D printing of scaffolding, we are able to control the external shape and internal architecture of scaffolds to maximize the anatomic fit, strength, and capability to deliver bioactive agents (35). Several approaches to 3D printing exist, such as, selective laser sintering, fused deposition modeling, stereolithography, and 3D plotting (49). The most widely used $3 \mathrm{D}$ printing technique is the fused-deposition additive technique, which can be categorized as inkjet, extrusion based, or laser-assisted (48). Calcium phosphate scaffolds have been $3 \mathrm{D}$ printed with inkjet-based printing, which has a downside of requiring high heat. These high temperatures prevent bioactive material from being incorporated into the scaffold architecture. Thus, the future of $3 \mathrm{D}$ printing of scaffolding is to produce ceramic polymer composites with low temperature, where a powder of calcium phosphate uses a water-based binder solution that is delivered from the inkjets through a dissolutionprecipitation reaction (35).

In an attempt to mimic the morphology, mechanical strength, function, and configuration of the ECM of the original skeleton, a varied range of electrospun bone regenerative nanofiber materials have been used. Electrospinning is an advanced method for attaining nanofibers from polymeric solutions (25). The process of constructing a scaffold through electrospinning nanofibers includes the application of high voltage to the polymer solution. An electrical field is created around the polymer when the voltage is applied, which creates a force that is larger than that of the solutions surface tension. A jet stream of polymer is created from this process which, due to the electrical instability, then flexes and lengthens causing a spiraling movement and a narrow diameter stream. Evaporation of the solvent results in a charged nanofiber polymer left behind. The nanofiber is drawn to a grounded collector, where it hardens into a woven mat. The orientation, thickness of individual nanofibers and of the overall matrix can be manipulated through solvent type, concentrations of the polymer, addition of surfactant, the type of collector used and time of electrospinning (35). Nanofibrous scaffolds allow for a more advantageous environment for tissue ingrowth at a cellular level and successive regeneration of bone as they are similar to collagen fibrils and have enhanced cellular attachment and proliferation (50). Tissue engineering in the craniomaxillofacial region is beginning to adopt the concept of nanofiber structures more and more as technology and knowledge advances.

Gas foaming and water leaching is another technique for scaffold fabrication. This technique involves the utilization of elevated pressures that when applied to polymers will melt and foam the material around porogens of a particular size. When organic solvents are used, solvent casting occurs, so the technique of gas foaming and water leaching will overcome this limitation. The technique involves the use of a high-pressured carbon dioxide around the polymers and porogens for a prolonged period of time. The carbon dioxide gas gets incorporated into the material, then a structured release of pressure creates a foaming process 
which forms a porous scaffold structure. Then the porous scaffold is placed in water which causes leaching of the porogen which is typically sugar or salt particles. After the porogen is leached, a sponge like structure is formed (48). The high levels of pressure and heat applied to polymers during compression limit the use of the gas foaming and water leaching technique (48).

No matter the makeup of these craniofacial scaffolds, they must be able to fit the multifaceted 3 dimensional anatomical defect, be permeable enough to transport bioactive factors, and sturdy enough to withstand forces until regenerated bone can assume this responsibility (35). Modern techniques and technology has made it possible to re-create the complex craniofacial structure using 3 dimensional printing with computer-aided design and computer-aided manufacturing.

\section{Stem cells}

During the bone healing process, precursor cells surrounding the craniofacial defect are fundamental to successful regeneration. Migration of these precursor cells to the defect site allows for differentiation into osteoblastic cells and endothelial cells encouraging bone formation and neovascularization (21). Reports in current literature have suggested that addition of stem cells may have a synergistic effect on progenitor cell migration and differentiation, allowing for better results during regeneration of critically sized craniofacial defects (21). The idea behind stem cells, is an undifferentiated cell having the capability of self-renewal and the ability to differentiate into one or more types of cell progeny (21) . Isolation of stems cells from embryonic, fetal, and adult tissues have been studied (51,52). Political and ethical disagreements have made the use of embryonic and fetal stem cells challenging, so at this time their studies are limited. However, adult stem cells have been studied extensively from multiple different tissue types. Adult stem cells can generally be placed in three categories; Hematopoietic, epithelial, and mesenchymal stem cells (MSCs). This review will focus on the adult MSCs which can be isolated from muscle, bone marrow, dermis, adipose tissue, trabecular bone periosteum, synovial membrane, blood, deciduous teeth and periodontal ligament $(51,52)$. MSCs have a potential for use in craniofacial tissue repair because these multipotent cells are proficient in transforming into bone, cartilage, fat, tendon and muscle. Today, the use of bone marrow has been the most widely accepted source of MSCs (51).

\section{Bone marrow-derived mesenchymal stem cells (BMSCs)}

BMSCs have displayed the ability to be effective as an osteoblastic precursor and are increasingly being used in defects of the craniofacial skeleton (21). BMSCs are thought of as an ideal source for craniofacial tissue engineering because there are no ethical or political controversies effecting their study and use; are normally easy to get a hold of; have expansion and self-renewal capabilities; have the ability to differentiate into necessary cell lineages appropriate to craniofacial skeleton; and hold little to no immunogenic or tumorigenic capabilities (21). Multiple studies have described bone formation when combining BMSCs with 3D scaffolds. These scaffolds included Hyaluronic acid/Chitosan composites, honeycomb collagen scaffolds, electrospun collagen nanofibers, chitosan or gelatin/TCP construct, and titanium meshes (53-58). A recent phase I/II randomized, controlled clinical trial was conducted to assess the restoration of maxillary bone deficits with transplantation of autologous cells, isolated from bone marrow. The isolate is enriched with Osteoblastic BMSCs $\left(\mathrm{CD} 90^{+}\right)$and $\mathrm{CD} 14^{+}$monocytes, which has the ability to induce vascular formation and ingrowth, incorporated into a $\beta$-Tricalcium phosphate scaffold which has been seeded with macrophages (59). The results of the study showed the safety and efficacy in enhancing tissue engineered bone quality by means of enriched $\mathrm{CD} 90^{+}$stem cell populations. What was found in this study was that in relation to the control group, the quality of bone formed was better and the quality positively correlated with the percentage of stem cells transplanted (59). A variety of studies have reported promising outcomes and advocate the practice of using BMSCs in repair of craniofacial skeletal defects.

\section{Adipose derived MSCs}

Prior to 2001 it was thought that the progenitor cells isolated from adipose tissue were limited to adipocytic lineage until Zuk et al. showed that they were able to isolate cells with multilineage potential from lipoaspirates (60). Now it is known that these adipocyte-derived stem cells (ASCs) can undergo osteogenesis as well (61). ASCs osteogenic potential has been studied through mixture with an array of different scaffold materials. For example, implanting ASCs onto HA/TCP or polyglycolic scaffolding may result in the development of an osteoid like material $(62,63)$. Reports by Dragoo described engineering of bone by ASCs with the help of $B M P-2(64,65)$. A concern of many of these studies was if the bone growth was due to the osteogenic growth 
factor or the ASCs. There has been no definitive answer and further studies must be conducted to conclude the true osteogenic capability of ASCs exclusive of the permutation of growth factors.

\section{Urine derived mesenchymal stem cells (USCs)}

USCs have captured the attention of many when it comes to an alternate source of stem cells for bone tissue engineering. Its exploration is still in the beginning stages, but current, studies by Guan et al. have revealed their potential application in the regeneration of bone (66-69). The appeal to USCs is the ease of obtaining it from urine and is noninvasive. USCs are comparable to ASCs biologically and are capable of osteogenic differentiation in vitro (69). There has been successful differentiation of USCs into osteoblasts via calcium silicate ion induction of the $\mathrm{Wnt} / ß$-catenin signaling pathway (66). Also, a study showed evidence that USCs were compatible with a B-TCP scaffold and capable of enhancing bone formation when they were implanted into segmental femoral defects of rats (66).

\section{Other adult MSC sources}

In addition to BMSCs, ASCs, and USCs multiple studies have shown the capabilities of MSCs derived from different craniofacial tissue that can form bone-like, cementumlike, and dentin-like structures (21). For instance, dental pulp stem cells (DPSCs) have been studied and shown effective in osteogenic potential in rat critical size calvarial defects (70). The study used a dense collagen gel scaffold permeated by mesenchymal DPSCs and placed in a rat calvarial defect. The mineral density and micro-architecture of the bone were significantly improved when a scaffold seeded by DPSCs was used. Microscopic evaluation revealed a dramatic improvement in mineralized and fibrous connective tissue (70). The results validate the potential benefit of bone healing by the use of DPSC-loaded-dense collagen gel scaffolds (71). Periodontal ligament stem cells (PDLSCs) isolated from extracted human $3^{\text {rd }}$ molars have shown differentiation into adipocytes and osteoblasts cell lineages in vitro and the ability to generate cementumlike configurations interfaced with dense collagen fibers in vivo $(72,73)$. Lastly, a loose ectomesenchymal tissue encompassing unerupted teeth known as the dental follicle, has been shown to contain progenitor cells and stem cells (74). Dental follicle stem cells (DFSCs) have strong differentiating potential toward the osteoblast lineage, which may prove to be useful in reconstruction of craniofacial skeletal defects (71). A study in rats evaluating bone regeneration capability of DFSCs isolated from the mandibular first molars, loaded into polycaprolactone (PCL) scaffold for management of craniofacial defects was conducted. The study showed bone restoration at 8 weeks in the skull of the rats treated with the DFSC transplantation but not in the control group (71). An Advantage of DFSCs is that there is no need for a second procedure, the follicle is isolated at the same time an impacted tooth is removed.

\section{Osteoinductive growth factors}

The integration of factors with biologic capabilities into scaffolding materials has been proposed to control the behavior of precursor cells to form new bone. For osteoblastic progenitor cells to differentiate after migrating to the defect site, it is essential to have osteoinductive factors. Enhancement of bone regeneration has been through the use of many growth factors. Some of these factors include vascular endothelial growth factor (VEGF), transforming growth factor $\beta(T G F-\beta)$, platelet derived growth factor $(P D G F)$, and fibroblast growth factor $(F G F)$. Bone morphogenetic proteins $(B M P \mathrm{~s})$, belonging to the $T G F-\beta$ superfamily, is the most investigated growth factor to date and has shown clinical success in bone regeneration of critically sized craniofacial defects (75). Over 20 different bone morphogenetic proteins have been discovered and studied, but osteoinductive properties have mainly been shown with $B M P$ s 2, 4, 6, 7 and 9. BMPs works through activation of chemotaxis, proliferation, and differentiation of osteoprogenitor cells, to induce the formation of bone (76). $B M P$ is unique in that it induces bone formation at the site of implantation instead of changing the growth rate of preexisting bone (77). Particularly recombinant human (rh)BMP-2 and $\operatorname{rh} B M P-7$ have been investigated thoroughly and received FDA approval. A system consisting of $\operatorname{rh} B M P-2$ on a scaffold of absorbable collage called InFUSE ${ }^{\circledR}$ system (Medtronic Sofamor Danek, Inc., Minneapolis, USA) and a $\operatorname{rh} B M P-7$ and bovine collagen altered with saline to form a paste called OP- $1^{\circledR}$ (Stryker Biotech). These two products have shown clinical success in studies of bony non-union $(78,79)$, bone defects $(80)$, open tibial fractures (81), and spinal fusions (82). One of the limiting factors to $B M P$ use has been the duration of $B M P$ s presence at the site of action. This is where the temporal and spatial control of the scaffold to deliver signaling molecules is necessary. Several preclinical models incorporating $\mathrm{rh} B M P$ onto scaffolds exist.

In recent years the discovery of the osteogenic 
potential of $B M P-9$ has been investigated and results are promising. It has been stated that out of the $B M P$ superfamily, $B M P-9$ may be the most potent osteogenic inducer (83). Previously, gene therapy through adenovirus transfection has been the only available $B M P-9$, but currently recombinant human $B M P-9$ has been developed with successful results and promising possibilities (83). A study was conducted investigating osteoblastic behavior when comparing $\operatorname{rh} B M P-9$ to $\operatorname{rh} B M P-2$ combined with bone grafting material. At the conclusion of the study, it was stated that both $\operatorname{rh} B M P-2$ and $\operatorname{rh} B M P-9$ promoted bone formation but rhBMP-9 demonstrated greater levels of alkaline phosphatase activity and alizarin red staining.. This greater level of alkaline phosphatase activity indicates greater activity of bone forming cells. Alizarin red staining, determines ECM mineralization, was increased in that of rhBMP-9 (84). Most studies on BMP-9 have been through the non-FDA approved gene therapy method, but with the development of $\operatorname{rh} B M P-9$ more studies are needed to evaluate its osteogenic potency.

Currently, the only use for $\operatorname{rh} B M P$ that has been approved by the FDA in craniofacial application is sinus augmentation. With an aim to assess the safety and clinical data for alveolar ridge and sinus augmentation in humans while using rhBMP-2 delivered on an absorbable collagen sponge carrier, a systemic review was conducted (85). Clinically meaningful bone regeneration resulted in maxillary sinus augmentation with $\operatorname{rh} B M P-2$ on an absorbable collagen sponge which would allow for the placement of dental implants (85). The comparison of rh $B M P-2$ on a collagen sponge scaffold versus autogenous bone grafting for maxillary sinus augmentation was assessed through randomized prospective trial with 160 subjects enrolled (86). The study looked into osteogenic potential, the osteointegration of implants, and functional loading capabilities at 6 months and at 2 years of implants placement. Both the groups showed a success rate of $79 \%$ with the rhBMP-2 group resulting in significantly denser bone. Additionally, complications were noted with the autograft group resulting in $17 \%$ long term paresthesia, gait disturbances, and pain at donor site (86).

A randomized, partially blinded clinical trial in 2001, by Friedlaender et al. compared rhBMP-7 on a type- 1 collagen sponge to anterior iliac crest bone graft (AICBG) in 124 tibial non-unions patients (78). Radiographic assessment disclosed that $75 \%$ of the rhBMP-7 treated non-unions and $84 \%$ of the AICBG-treated non-unions had recovered fractures. The infection rate in the study was greater (14\%) in the AICBG group compared to the rhBMP-7 group (4.9\%). Twenty percent of persistent donor site pain was noted by the authors at 6 months post op in AICBG group (78).

Allogenic bone mixed with $\operatorname{rh} B M P-2$ and bone marrow aspirate concentrate were used to restore mandibular defects in a retrospective case series that enrolled 34 patients over a 5 -year period (87). The clinical success of the study was evaluated using specific criteria. These criteria include: (I) bone union, which was defined as homogenous radiographic appearance without mandibular mobility; (II) the grafted site has adequate volume of bone that allows for implant placement. At the 6 month mark, CT scans and clinical exams were performed resulting in $90 \%$ success with the average height that was gained being $2.12 \pm 0.64 \mathrm{~cm}$ and width of $1.53 \pm 0.46 \mathrm{~cm}$. The report established that although the use of autogenous graft remains the gold standard, the developing science behind clinical tissue engineering has shown clinical success for craniofacial defects with less morbidity than autogenous grafting (87).

Another study examined the result of polymer capsules containing recombinant human bone morphogenetic protein-2 ( $\mathrm{rh} B M P-2)$ on regeneration of bone in large segmental defects in rats. The study imbedded PGA capsules containing rhBMP-2 in a $5 \mathrm{~mm}$ segmental defect in the femur of rats. 8 weeks post implantation, they discovered radiographic and histologic evidence of bony union, while the control group showed no bridging in the defect (88).

In 2015 Augment bone graft $^{\circledR}(\operatorname{rh} P D G F-B B)$ was approved for hindfoot and ankle fusion (89). PDGF acts on the $P D G F$ receptor which activates a cascade that in turn stimulates recruitment and proliferation of cells, including MSCs. It also promotes neovascularization at the healing site by increasing pericytes, vascular endothelial cells, and smooth muscle cell responses (90). A recent clinical study focusing on $\operatorname{rh} P D G F-B B$ with $\beta$-TCP scaffold in 434 patients devoted to hindfoot or ankle arthrodesis. In comparison to autografts, the study results showed similar fusion rates, significantly less pain, and decreased side effects (91). The results could prove to be promising in the future of craniofacial bone regeneration.

Growth factor integration into scaffolds can be achieved in many ways. Saturating the scaffold in growth factor containing solution will cause a loose relationship. This loose relationship between the materials results in a rapid release of the chosen growth factor (92). Growth factors can also be manufactured to create an extended release effect by covalently linking them to the scaffolds microstructure. 
This has successfully been implemented in animal studies to reconstruct defects in areas of the mandible, calvaria, and zygoma $(92,93)$. A similar effect can be achieved with cells that are modified through gene therapy to express and secrete growth factors with osteoinductive potential (94).

Supplementing osteoinductive growth factors is possible through the use of small molecules that assistance in inducing differentiation of osteoblasts. These small molecules have the benefit of: being cost effective; simpler to manufacture and handle; and able to diffuse rapidly into the surrounding architecture (95). Statins, along with other immunosuppressants, are small molecules that have been studied and showed the ability to encourage osteoblastic differentiation and formation of new bone (96-99). One small molecule that has exhibited the ability to encourage osteogenesis in BMSCs and in dental pulp cells through $B M P$ signaling pathway activation, is a molecule called Phenamil. This molecule is an irreversible equivalent of amiloride (100-103). In calvarial defect repairs, Phenamil has recently demonstrated a synergistic effect with $B M P-2$ through the induction of osteogenic differentiation of ASCs (104). Another molecule that may be used in complement with BMP is NELL1. NELL1 is a gene that has a markedly different effect on osteoblastic differentiation than BMP-2 (105). When NELL1 and BMP-2 were implanted in vivo into rat calvarial defects, they showed no apparent difference in the bone regeneration capacity on micro-computed tomography or evaluation of histology. These findings may suggest that both NELL1 and BMP-2 use different pathways to induce the differentiation of osteoblasts $(105,106)$. A study evaluating bone regeneration capacity when combining NELL1 and BMP-2, showed more complete regeneration with more mature bone when compared to BMP-2 on its own (107).

Although clinical studies of osteoinductive growth factors have shown promising results, there have been concerns that due to the quick diffusion, insufficient solubility of the carrier within the defect, and effects of proteolytic degradation, the half-life is too short (108). In order to address this issue, some proposed gene therapy to induce a sustained release of growth factor increase the time spent inducing its effect at the desired site.

\section{Gene therapy}

An alternative to transporting growth factors into defective sites, is through gene delivery. This technique involves transferring a desired gene encoding for specific growth factors into the defect site using vectors that carry the gene. Then, in vivo, the cells that were transfected by vectors carrying the gene, produce the target molecule and secrete it into the defect site (109). The release period of the drug can be controlled by the vector carrying the gene (109). Gene delivery can be accomplished through ex vivo delivery and in vivo delivery. In vivo delivery is able to directly transfer genes into the host, while ex vivo delivery is a cellbased gene delivery; in that it transduces harvested cells from the host with a vector carrying the target genes, and then the transduced cells are directed to the defect site (109).

In ex vivo BMP-2 gene delivery, multiple types of MSC-derived cells are used as gene carriers. Like bone marrow stromal cells (BMSCs), ASCs, PDLSCs, and fibroblasts (110-116). BMP-2 gene delivery for regeneration of bone via ex vivo delivery, resulted in complete closure of calvarial defect within 4 weeks, unlike the in vivo delivery technique $(112,113)$. During in vivo $B M P-2$ gene delivery, direct injection of the genetic material can be applied, but it has been shown that fast diffusion rate, nonspecific biodistribution, rapid rate of enzymatic degradation, and little uptake by cells does not permit for the production of the desired effect (117). There have also been concerns with the excessive amounts of adenovirus that needs to be injected directly into the defect site to induce bone regeneration. The large viral load required in the in vivo delivery method is thought to lead to an excessive immune reaction (118).

BMSCs have shown promise in the field of gene therapy. MSCs have the ability to be transduced, giving them potential to aid as vehicles for either long-term or shortterm therapeutic gene transfer (119). Several studies have revealed that virus-based $B M P$ expression vectors can encourage differentiation of osteoblasts and the formation of new bone in vivo (120-122). In a study investigating spine fusion in rat models, Peterson et al. demonstrated that successful fusion could take place in human BMSCs infected with BMP-2 containing adenovirus (123). This is an important discovery because it has been shown that the administration of supraphysiologic doses of $B M P$ would actually stimulate bone resorption and turnover instead $(122,124)$. Therefore, site specific administration of physiologic doses of $B M P$ can be ensured by utilizing MSCs as a delivery vehicle.

In recent years, curiosity in ASCs for $B M P-2$ gene delivery has been growing. ASCs are advantageous due to their accessibility and availability; however, they also have restraints due to their low stemness and multipotency (125). 
It has been stated that $B M P-2$ production and osteogenic differentiation capability in ASCs were greater than those in BMSCs in in vitro studies (126).

Ex vivo gene delivery of osteoblasts and fibroblast derived from MSCs has also been researched. Hirata $e t$ al. reported findings of successful regeneration of bone in rat calvarial defects by taking advantage of skin fibroblasts for gene delivery (127). Keeney et al. applied skull-based osteoblasts for BMP-2 gene delivery (128). Shin et al. witness complete closure of defects in rat calvaria within 4 weeks after implanting human gingival fibroblasts transfected with adenovirus containing $B M P-2$ (129).

In $B M P-2$ gene delivery, irrespective of whether it is ex vivo or in vivo, viral and non-viral vectors can be employed equally. The aspects of viral vectors that give them an advantage includes the high efficiency in transduction of genes and ability to target dividing or non-dividing cells $(130,131)$. The negatives surrounding viral vectors are the difficult manufacturing techniques, their potential to cause immune reactions to the virus (132), and the accompanying safety concerns $(133,134)$. The advantages of the non-viral vectors are the simplicity in manufacturing, low costs, and low immunogenicity. The disadvantages include the limited efficiency of in vivo gene transduction (131), the high amounts required to induce therapeutic effects, their limited ability to focus on specific cell types, and potential material toxicity (110).

Combined approaches to include both osteogenesis and angiogenesis have been shown to improve bone regeneration in critically sized defects. He et al. transfected MSCs and endothelial progenitor cells (EPCs) with adenoviral vectors containing $B M P-2$ (135). This resulted in increased osteogenesis and neovascularization in rat calvarial defects. Other findings presented a synergistic effect with $B M P-2 / V E G F$ gene delivery in comparison to those in the $B M P-2$ alone group (136-138).

Achieving craniomaxillofacial bone regeneration through gene therapy, efficient vector systems with reduced immunogenicity, and a stable cell supply has a great potential future while safety concerns must be addressed.

\section{Conclusions}

Craniofacial bone regeneration has progressed significantly over the last two decades and is continuously adopting new techniques and biomaterials to advance our ability to re-create the structures of the complex craniofacial unit. Advances have been made in the fields of stem cell biology, developmental biology, biomedical engineering, and mechanical engineering. These advances have allowed the investigations into ways to: isolate and utilize different stem cell sources; develop scaffolding material and designs that nears ideal properties; develop different strategies for sophisticated gene delivery methods; and utilize growth factors to enhance our ability to regenerate bone.

Although autologous grafting is still measured as the gold standard for craniofacial reconstruction, many studies believe advances in techniques through tissue engineering, stem cell biology and gene therapy will be the future. Combining biomaterials to optimize properties of Scaffolds and improving structure through more environmentally friendly bio-based materials and computer aided designs are allowing us to mimic the configuration, morphologic traits and mechanical function of the ECM of native bone. Advances in exposing the osteogenic potential in numerous stem cell types, as well as discovering sources of stem cells that are more easily accessible and abundant are offering exciting outlooks for craniofacial bone regeneration. Incorporation of growth factors, especially $B M P$, have been studied extensively and have repeatedly shown promise in their ability to enhance bone regeneration. Innovations in gene delivery methods and vectors have a potential in bone regeneration but concerns with its safety still exist and must be addressed before it can replace autologous grafting techniques. Despite such advances, relatively little research investigates the ability of tissue engineering approaches to reconstruct defects in patients with compromised healing potential or those with extensive medical comorbidities. Although promising, alternatives to autologous grafting for craniofacial bone regeneration still require refinement in strategies and materials to attain more consistent outcomes and to report the numerous challenges posed by real clinical scenarios.

\section{Acknowledgments}

Writing or language editing assistance: this work was supported by Nilam Ghori and Shereen Abdelhak.

Funding: None.

\section{Footnote}

Provenance and Peer Review: This article was commissioned by the Guest Editor (Sung-Kiang Chuang) for the series "Clinical Outcomes and Innovations in Oral and Maxillofacial Surgery" published in Frontiers of Oral and 
Maxillofacial Medicine. The article has undergone external peer review.

Reporting Checklist: The authors have completed the Narrative Review reporting checklist. Available at https:// fomm.amegroups.com/article/view/10.21037/fomm-21-9/rc

Conflicts of Interest: Both authors have completed the ICMJE uniform disclosure form (available at https://fomm. amegroups.com/article/view/10.21037/fomm-21-9/coif). The series "Clinical Outcomes and Innovations in Oral and Maxillofacial Surgery" was commissioned by the editorial office without any funding or sponsorship. JH serves as an unpaid editorial board member of Frontiers of Oral and Maxillofacial Medicine. The authors have no other conflicts of interest to declare.

Ethical Statement: The authors are accountable for all aspects of the work in ensuring that questions related to the accuracy or integrity of any part of the work are appropriately investigated and resolved.

Open Access Statement: This is an Open Access article distributed in accordance with the Creative Commons Attribution-NonCommercial-NoDerivs 4.0 International License (CC BY-NC-ND 4.0), which permits the noncommercial replication and distribution of the article with the strict proviso that no changes or edits are made and the original work is properly cited (including links to both the formal publication through the relevant DOI and the license). See: https://creativecommons.org/licenses/by-nc-nd/4.0/.

\section{References}

1. Schmitz JP, Hollinger JO. The critical size defect as an experimental model for craniomandibulofacial nonunions. Clin Orthop Relat Res 1986;(205):299-308.

2. Dimitriou R, Jones E, McGonagle D, et al. Bone regeneration: current concepts and future directions. BMC Med 2011;9:66.

3. Tessier P, Kawamoto H, Matthews D, et al. Autogenous bone grafts and bone substitutes--tools and techniques: I. A 20,000-case experience in maxillofacial and craniofacial surgery. Plast Reconstr Surg 2005;116:6S-24S.

4. Dimitriou R, Mataliotakis GI, Angoules AG, et al. Complications following autologous bone graft harvesting from the iliac crest and using the RIA: a systematic review. Injury 2011;42 Suppl 2:S3-15.
5. Zouhary KJ. Bone graft harvesting from distant sites: concepts and techniques. Oral Maxillofac Surg Clin North Am 2010;22:301-16, v.

6. Blum KS, Schneider SJ, Rosenthal AD. Methyl methacrylate cranioplasty in children: long-term results. Pediatr Neurosurg 1997;26:33-5.

7. Nevins M, Camelo M, Nevins ML, et al. Periodontal regeneration in humans using recombinant human platelet-derived growth factor-BB (rhPDGF-BB) and allogenic bone. J Periodontol 2003;74:1282-92.

8. Gille J, Dorn B, Kekow J, et al. Bone substitutes as carriers for transforming growth factor-beta(1) (TGF-beta(1)). Int Orthop 2002;26:203-6.

9. Yamada Y, Ueda M, Naiki T, et al. Tissue-engineered injectable bone regeneration for osseointegrated dental implants. Clin Oral Implants Res 2004;15:589-97.

10. Gault P, Black A, Romette JL, et al. Tissue-engineered ligament: implant constructs for tooth replacement. J Clin Periodontol 2010;37:750-8.

11. d'Aquino R, De Rosa A, Lanza V, et al. Human mandible bone defect repair by the grafting of dental pulp stem/ progenitor cells and collagen sponge biocomplexes. Eur Cell Mater 2009;18:75-83.

12. Chang PC, Cirelli JA, Jin Q, et al. Adenovirus encoding human platelet-derived growth factor-B delivered to alveolar bone defects exhibits safety and biodistribution profiles favorable for clinical use. Hum Gene Ther 2009;20:486-96.

13. Breitbart AS, Grande DA, Mason JM, et al. Geneenhanced tissue engineering: applications for bone healing using cultured periosteal cells transduced retrovirally with the BMP-7 gene. Ann Plast Surg 1999;42:488-95.

14. Laurencin CT, Attawia MA, Lu LQ, et al. Poly(lactideco-glycolide)/hydroxyapatite delivery of BMP-2producing cells: a regional gene therapy approach to bone regeneration. Biomaterials 2001;22:1271-7.

15. Soltan M, Smiler D, Prasad HS, et al. Bone block allograft impregnated with bone marrow aspirate. Implant Dent 2007;16:329-39.

16. Kawaguchi H, Hirachi A, Hasegawa N, et al. Enhancement of periodontal tissue regeneration by transplantation of bone marrow mesenchymal stem cells. J Periodontol 2004;75:1281-7.

17. Marei MK, Nouh SR, Saad MM, et al. Preservation and regeneration of alveolar bone by tissue-engineered implants. Tissue Eng 2005;11:751-67.

18. Filho Cerruti H, Kerkis I, Kerkis A, et al. Allogenous bone grafts improved by bone marrow stem cells and 
platelet growth factors: clinical case reports. Artif Organs 2007;31:268-73.

19. Yamada Y, Ueda M, Hibi H, et al. Translational research for injectable tissue-engineered bone regeneration using mesenchymal stem cells and platelet-rich plasma: from basic research to clinical case study. Cell Transplant 2004;13:343-55.

20. Langer R, Vacanti JP. Tissue engineering. Science 1993;260:920-6.

21. Shanti RM, Li WJ, Nesti LJ, et al. Adult mesenchymal stem cells: biological properties, characteristics, and applications in maxillofacial surgery. J Oral Maxillofac Surg 2007;65:1640-7.

22. Hibi H, Yamada Y, Ueda M, et al. Alveolar cleft osteoplasty using tissue-engineered osteogenic material. Int J Oral Maxillofac Surg 2006;35:551-5.

23. Shayesteh YS, Khojasteh A, Soleimani M, et al. Sinus augmentation using human mesenchymal stem cells loaded into a beta-tricalcium phosphate/hydroxyapatite scaffold. Oral Surg Oral Med Oral Pathol Oral Radiol Endod 2008;106:203-9.

24. Carstens $\mathrm{MH}$, Chin $\mathrm{M}, \mathrm{Ng}$ T, et al. Reconstruction of \#7 facial cleft with distraction-assisted in situ osteogenesis (DISO): role of recombinant human bone morphogenetic protein-2 with Helistat-activated collagen implant. J Craniofac Surg 2005;16:1023-32.

25. Petrovic V, Zivkovic P, Petrovic D, et al. Craniofacial bone tissue engineering. Oral Surg Oral Med Oral Pathol Oral Radiol 2012;114:e1-9.

26. Giesen EB, Ding M, Dalstra M, et al. Changed morphology and mechanical properties of cancellous bone in the mandibular condyles of edentate people. J Dent Res 2004;83:255-9.

27. Meinel L, Karageorgiou V, Hofmann S, et al. Engineering bone-like tissue in vitro using human bone marrow stem cells and silk scaffolds. J Biomed Mater Res A 2004;71:25-34.

28. Hollister SJ. Porous scaffold design for tissue engineering. Nat Mater 2005;4:518-24.

29. Mao JJ, Giannobile WV, Helms JA, et al. Craniofacial tissue engineering by stem cells. J Dent Res 2006;85:966-79.

30. Gersbach CA, Coyer SR, Le Doux JM, et al. Biomaterialmediated retroviral gene transfer using self-assembled monolayers. Biomaterials 2007;28:5121-7.

31. Hutmacher DW, Cool S. Concepts of scaffold-based tissue engineering--the rationale to use solid free-form fabrication techniques. J Cell Mol Med 2007;11:654-69.

32. Hutmacher DW, Schantz JT, Lam CX, et al. State of the art and future directions of scaffold-based bone engineering from a biomaterials perspective. J Tissue Eng Regen Med 2007;1:245-60.

33. Wang X, Hu X, Daley A, et al. Nanolayer biomaterial coatings of silk fibroin for controlled release. J Control Release 2007;121:190-9.

34. Jones AC, Arns CH, Hutmacher DW, et al. The correlation of pore morphology, interconnectivity and physical properties of $3 \mathrm{D}$ ceramic scaffolds with bone ingrowth. Biomaterials 2009;30:1440-51.

35. Tevlin R, McArdle A, Atashroo D, et al. Biomaterials for craniofacial bone engineering. J Dent Res 2014;93:1187-95.

36. Solchaga LA, Gao J, Dennis JE, et al. Treatment of osteochondral defects with autologous bone marrow in a hyaluronan-based delivery vehicle. Tissue Eng 2002;8:333-47.

37. Abbah SA, Lu WW, Chan D, et al. In vitro evaluation of alginate encapsulated adipose-tissue stromal cells for use as injectable bone graft substitute. Biochem Biophys Res Commun 2006;347:185-91.

38. Chang SH, Hsu YM, Wang YJ, et al. Fabrication of pre-determined shape of bone segment with collagenhydroxyapatite scaffold and autogenous platelet-rich plasma. J Mater Sci Mater Med 2009;20:23-31.

39. Chesnutt BM, Yuan Y, Buddington K, et al. Composite chitosan/nano-hydroxyapatite scaffolds induce osteocalcin production by osteoblasts in vitro and support bone formation in vivo. Tissue Eng Part A 2009; 15:2571-9.

40. Tollemar V, Collier ZJ, Mohammed MK, et al. Stem cells, growth factors and scaffolds in craniofacial regenerative medicine. Genes Dis 2016;3:56-71.

41. Schwartz C, Liss P, Jacquemaire B, et al. Biphasic synthetic bone substitute use in orthopaedic and trauma surgery: clinical, radiological and histological results. J Mater Sci Mater Med 1999;10:821-5.

42. Yusop AH, Bakir AA, Shaharom NA, et al. Porous biodegradable metals for hard tissue scaffolds: a review. Int J Biomater 2012;2012:641430.

43. Witte F, Kaese V, Haferkamp H, et al. In vivo corrosion of four magnesium alloys and the associated bone response. Biomaterials 2005;26:3557-63.

44. Ni S, Chang J, Chou L. A novel bioactive porous CaSiO3 scaffold for bone tissue engineering. J Biomed Mater Res A 2006;76:196-205.

45. Wang C, Lin K, Chang J, et al. Osteogenesis and angiogenesis induced by porous $\beta-\mathrm{CaSiO}(3) / \mathrm{PDLGA}$ composite scaffold via activation of AMPK/ERK1/2 and PI3K/Akt pathways. Biomaterials 2013;34:64-77.

46. Sun J, Wei L, Liu X, et al. Influences of ionic dissolution products of dicalcium silicate coating on osteoblastic 
proliferation, differentiation and gene expression. Acta Biomater 2009;5:1284-93.

47. Babu RP, O'Connor K, Seeram R. Current progress on bio-based polymers and their future trends. Prog Biomater 2013;2:8.

48. Rahman SU, Nagrath M, Ponnusamy S, et al. Nanoscale and Macroscale Scaffolds with Controlled-Release Polymeric Systems for Dental Craniomaxillofacial Tissue Engineering. Materials (Basel) 2018;11:1478.

49. Chia HN, Wu BM. Recent advances in $3 \mathrm{D}$ printing of biomaterials. J Biol Eng 2015;9:4.

50. Bhattarai SR, Bhattarai N, Yi HK, et al. Novel biodegradable electrospun membrane: scaffold for tissue engineering. Biomaterials 2004;25:2595-602.

51. Pittenger MF, Mackay AM, Beck SC, et al. Multilineage potential of adult human mesenchymal stem cells. Science 1999;284:143-7.

52. Caterson EJ, Nesti LJ, Danielson KG, et al. Human marrow-derived mesenchymal progenitor cells: isolation, culture expansion, and analysis of differentiation. Mol Biotechnol 2002;20:245-56.

53. George J, Kuboki Y, Miyata T. Differentiation of mesenchymal stem cells into osteoblasts on honeycomb collagen scaffolds. Biotechnol Bioeng 2006;95:404-11.

54. Holtorf HL, Datta N, Jansen JA, et al. Scaffold mesh size affects the osteoblastic differentiation of seeded marrow stromal cells cultured in a flow perfusion bioreactor. J Biomed Mater Res A 2005;74:171-80.

55. Okamoto M, Dohi Y, Ohgushi H, et al. Influence of the porosity of hydroxyapatite ceramics on in vitro and in vivo bone formation by cultured rat bone marrow stromal cells. J Mater Sci Mater Med 2006;17:327-36.

56. Oliveira JM, Rodrigues MT, Silva SS, et al. Novel hydroxyapatite/chitosan bilayered scaffold for osteochondral tissue-engineering applications: Scaffold design and its performance when seeded with goat bone marrow stromal cells. Biomaterials 2006;27:6123-37.

57. Shih YR, Chen CN, Tsai SW, et al. Growth of mesenchymal stem cells on electrospun type I collagen nanofibers. Stem Cells 2006;24:2391-7.

58. Takahashi Y, Yamamoto M, Tabata Y. Osteogenic differentiation of mesenchymal stem cells in biodegradable sponges composed of gelatin and beta-tricalcium phosphate. Biomaterials 2005;26:3587-96.

59. Kaigler D, Avila-Ortiz G, Travan S, et al. Bone Engineering of Maxillary Sinus Bone Deficiencies Using Enriched CD90+ Stem Cell Therapy: A Randomized Clinical Trial. J Bone Miner Res 2015;30:1206-16.
60. Zuk PA, Zhu M, Ashjian P, et al. Human adipose tissue is a source of multipotent stem cells. Mol Biol Cell 2002;13:4279-95.

61. Zuk PA. Tissue engineering craniofacial defects with adult stem cells? Are we ready yet? Pediatr Res 2008;63:478-86.

62. Hicok KC, Du Laney TV, Zhou YS, et al. Human adiposederived adult stem cells produce osteoid in vivo. Tissue Eng 2004;10:371-80.

63. Lee JA, Parrett BM, Conejero JA, et al. Biological alchemy: engineering bone and fat from fat-derived stem cells. Ann Plast Surg 2003;50:610-7.

64. Dragoo JL, Choi JY, Lieberman JR, et al. Bone induction by BMP-2 transduced stem cells derived from human fat. J Orthop Res 2003;21:622-9.

65. Dragoo JL, Lieberman JR, Lee RS, et al. Tissueengineered bone from BMP-2-transduced stem cells derived from human fat. Plast Reconstr Surg 2005;115:1665-73.

66. Guan J, Zhang J, Guo S, et al. Human urine-derived stem cells can be induced into osteogenic lineage by silicate bioceramics via activation of the $\mathrm{Wnt} / \beta$-catenin signaling pathway. Biomaterials 2015;55:1-11.

67. Guan J, Zhang J, Zhu Z, et al. Bone morphogenetic protein 2 gene transduction enhances the osteogenic potential of human urine-derived stem cells. Stem Cell Res Ther 2015;6:5.

68. Guan J, Zhang J, Li H, et al. Human Urine Derived Stem Cells in Combination with $\beta$-TCP Can Be Applied for Bone Regeneration. PLoS One 2015;10:e0125253.

69. Guan JJ, Niu X, Gong FX, et al. Biological characteristics of human-urine-derived stem cells: potential for cell-based therapy in neurology. Tissue Eng Part A 2014;20:1794-806.

70. Chamieh F, Collignon AM, Coyac BR, et al. Accelerated craniofacial bone regeneration through dense collagen gel scaffolds seeded with dental pulp stem cells. Sci Rep 2016;6:38814.

71. Yao S, He H, Gutierrez DL, et al. Expression of bone morphogenetic protein- 6 in dental follicle stem cells and its effect on osteogenic differentiation. Cells Tissues Organs 2013;198:438-47.

72. Shi S, Gronthos S, Chen S, et al. Bone formation by human postnatal bone marrow stromal stem cells is enhanced by telomerase expression. Nat Biotechnol 2002;20:587-91.

73. Seo BM, Miura M, Gronthos S, et al. Investigation of multipotent postnatal stem cells from human periodontal ligament. Lancet 2004;364:149-55.

74. Rezai-Rad M, Bova JF, Orooji M, et al. Evaluation 
of bone regeneration potential of dental follicle stem cells for treatment of craniofacial defects. Cytotherapy 2015;17:1572-81.

75. Reddi AH. BMPs: from bone morphogenetic proteins to body morphogenetic proteins. Cytokine Growth Factor Rev 2005;16:249-50.

76. Nauth A, Ristevski B, Li R, et al. Growth factors and bone regeneration: how much bone can we expect? Injury 2011;42:574-9.

77. Urist MR. Bone: formation by autoinduction. Science 1965;150:893-9.

78. Friedlaender GE, Perry CR, Cole JD, et al. Osteogenic protein-1 (bone morphogenetic protein-7) in the treatment of tibial nonunions. J Bone Joint Surg Am 2001;83-A Suppl 1:S151-8.

79. Zimmermann G, Wagner C, Schmeckenbecher K, et al. Treatment of tibial shaft non-unions: bone morphogenetic proteins versus autologous bone graft. Injury 2009;40 Suppl 3:S50-3.

80. Ekrol I, Hajducka C, Court-Brown C, et al. A comparison of RhBMP-7 (OP-1) and autogenous graft for metaphyseal defects after osteotomy of the distal radius. Injury 2008;39 Suppl 2:S73-82.

81. Govender S, Csimma C, Genant HK, et al. Recombinant human bone morphogenetic protein-2 for treatment of open tibial fractures: a prospective, controlled, randomized study of four hundred and fifty patients. J Bone Joint Surg Am 2002;84:2123-34.

82. Vaccaro AR, Patel T, Fischgrund J, et al. A pilot study evaluating the safety and efficacy of OP-1 Putty (rhBMP-7) as a replacement for iliac crest autograft in posterolateral lumbar arthrodesis for degenerative spondylolisthesis. Spine (Phila Pa 1976) 2004;29:1885-92.

83. Saulacic N, Fujioka-Kobayashi M, Kobayashi E, et al. Guided bone regeneration with recombinant human bone morphogenetic protein 9 loaded on either deproteinized bovine bone mineral or a collagen barrier membrane. Clin Implant Dent Relat Res 2017;19:600-7.

84. Fujioka-Kobayashi M, Sawada K, Kobayashi E, et al. Osteogenic potential of rhBMP9 combined with a bovinederived natural bone mineral scaffold compared to rhBMP2. Clin Oral Implants Res 2017;28:381-7.

85. Freitas RM, Spin-Neto R, Marcantonio Junior E, et al. Alveolar ridge and maxillary sinus augmentation using rhBMP-2: a systematic review. Clin Implant Dent Relat Res 2015;17 Suppl 1:e192-201.

86. Ward BB, Brown SE, Krebsbach PH. Bioengineering strategies for regeneration of craniofacial bone: a review of emerging technologies. Oral Dis 2010;16:709-16.

87. Melville JC, Tran HQ, Bhatti AK, et al. Is Reconstruction of Large Mandibular Defects Using Bioengineering Materials Effective? J Oral Maxillofac Surg 2020;78:661. e1-661.e29.

88. Isobe M, Yamazaki Y, Mori M, et al. Bone regeneration produced in rat femur defects by polymer capsules containing recombinant human bone morphogenetic protein-2. J Oral Maxillofac Surg 1999;57:695-8; discussion 699.

89. Ho-Shui-Ling A, Bolander J, Rustom LE, et al. Bone regeneration strategies: Engineered scaffolds, bioactive molecules and stem cells current stage and future perspectives. Biomaterials 2018;180:143-62.

90. Ozaki Y, Nishimura M, Sekiya K, et al. Comprehensive analysis of chemotactic factors for bone marrow mesenchymal stem cells. Stem Cells Dev 2007;16:119-29.

91. DiGiovanni CW, Lin SS, Baumhauer JF, et al. Recombinant human platelet-derived growth factor-BB and beta-tricalcium phosphate (rhPDGF-BB/ $\beta$-TCP): an alternative to autogenous bone graft. J Bone Joint Surg Am 2013;95:1184-92.

92. Fishero BA, Kohli N, Das A, et al. Current concepts of bone tissue engineering for craniofacial bone defect repair. Craniomaxillofac Trauma Reconstr 2015;8:23-30.

93. Fong KD, Nacamuli RP, Song HM, et al. New strategies for craniofacial repair and replacement: a brief review. J Craniofac Surg 2003;14:333-9.

94. Amini AR, Laurencin CT, Nukavarapu SP. Bone tissue engineering: recent advances and challenges. Crit Rev Biomed Eng 2012;40:363-408.

95. Laurencin CT, Ashe KM, Henry N, et al. Delivery of small molecules for bone regenerative engineering: preclinical studies and potential clinical applications. Drug Discov Today 2014;19:794-800.

96. Mundy G, Garrett R, Harris S, et al. Stimulation of bone formation in vitro and in rodents by statins. Science 1999;286:1946-9.

97. Zhou Y, Ni Y, Liu Y, et al. The role of simvastatin in the osteogenesis of injectable tissue-engineered bone based on human adipose-derived stromal cells and platelet-rich plasma. Biomaterials 2010;31:5325-35.

98. Dai W, Dong J, Fang T, et al. Stimulation of osteogenic activity in mesenchymal stem cells by FK506. J Biomed Mater Res A 2008;86:235-43.

99. Isomoto S, Hattori K, Ohgushi H, et al. Rapamycin as an inhibitor of osteogenic differentiation in bone marrowderived mesenchymal stem cells. J Orthop Sci 2007;12:83-8. 
100.Park KW, Waki H, Kim WK, et al. The small molecule phenamil induces osteoblast differentiation and mineralization. Mol Cell Biol 2009;29:3905-14.

101.Lo KW, Ulery BD, Kan HM, et al. Evaluating the feasibility of utilizing the small molecule phenamil as a novel biofactor for bone regenerative engineering. J Tissue Eng Regen Med 2014;8:728-36.

102.Kim JG, Son KM, Park HC, et al. Stimulating effects of quercetin and phenamil on differentiation of human dental pulp cells. Eur J Oral Sci 2013;121:559-65.

103.Lo KW, Kan HM, Laurencin CT. Short-term administration of small molecule phenamil induced a protracted osteogenic effect on osteoblast-like MC3T3-E1 cells. J Tissue Eng Regen Med 2016;10:518-26.

104. Fan J, Im CS, Cui ZK, et al. Delivery of Phenamil Enhances BMP-2-Induced Osteogenic Differentiation of Adipose-Derived Stem Cells and Bone Formation in Calvarial Defects. Tissue Eng Part A 2015;21:2053-65.

105.Aghaloo T, Cowan CM, Chou YF, et al. Nell-1-induced bone regeneration in calvarial defects. Am J Pathol 2006;169:903-15.

106. Cowan CM, Jiang X, Hsu T, et al. Synergistic effects of Nell-1 and BMP-2 on the osteogenic differentiation of myoblasts. J Bone Miner Res 2007;22:918-30.

107.Aghaloo T, Cowan CM, Zhang X, et al. The effect of NELL1 and bone morphogenetic protein-2 on calvarial bone regeneration. J Oral Maxillofac Surg 2010;68:300-8.

108. Giannobile WV. Periodontal tissue engineering by growth factors. Bone 1996;19:23S-37S.

109. Park SY, Kim KH, Kim S, et al. BMP-2 Gene DeliveryBased Bone Regeneration in Dentistry. Pharmaceutics 2019;11:393.

110.Moghimi SM, Symonds P, Murray JC, et al. A two-stage poly(ethylenimine)-mediated cytotoxicity: implications for gene transfer/therapy. Mol Ther 2005;11:990-5.

111.Park J, Ries J, Gelse K, et al. Bone regeneration in critical size defects by cell-mediated BMP-2 gene transfer: a comparison of adenoviral vectors and liposomes. Gene Ther 2003;10:1089-98.

112.Lee JY, Musgrave D, Pelinkovic D, et al. Effect of bone morphogenetic protein-2-expressing muscle-derived cells on healing of critical-sized bone defects in mice. J Bone Joint Surg Am 2001;83:1032-9.

113. Lee JY, Peng H, Usas A, et al. Enhancement of bone healing based on ex vivo gene therapy using human muscle-derived cells expressing bone morphogenetic protein 2. Hum Gene Ther 2002;13:1201-11.

114.Xu L, Sun X, Bai J, et al. Reosseointegration Following
Regenerative Therapy of Tissue-Engineered Bone in a Canine Model of Experimental Peri-Implantitis. Clin Implant Dent Relat Res 2016;18:379-91.

115.Park SY, Kim KH, Gwak EH, et al. Ex vivo bone morphogenetic protein 2 gene delivery using periodontal ligament stem cells for enhanced re-osseointegration in the regenerative treatment of peri-implantitis. J Biomed Mater Res A 2015;103:38-47.

116.Lu CH, Chang YH, Lin SY, et al. Recent progresses in gene delivery-based bone tissue engineering. Biotechnol Adv 2013;31:1695-706.

117.Heitz-Mayfield LJ, Lang NP. Comparative biology of chronic and aggressive periodontitis vs. peri-implantitis. Periodontol 2000 2010;53:167-81.

118.Zhang Y, Satterlee A, Huang L. In vivo gene delivery by nonviral vectors: overcoming hurdles? Mol Ther 2012;20:1298-304.

119. Javazon EH, Beggs KJ, Flake AW. Mesenchymal stem cells: paradoxes of passaging. Exp Hematol 2004;32:414-25.

120. Franceschi RT, Yang S, Rutherford RB, et al. Gene therapy approaches for bone regeneration. Cells Tissues Organs 2004;176:95-108.

121. Gazit D, Turgeman G, Kelley P, et al. Engineered pluripotent mesenchymal cells integrate and differentiate in regenerating bone: a novel cell-mediated gene therapy. J Gene Med 1999;1:121-33.

122. Chang SC, Wei FC, Chuang H, et al. Ex vivo gene therapy in autologous critical-size craniofacial bone regeneration. Plast Reconstr Surg 2003;112:1841-50.

123.Peterson B, Iglesias R, Zhang J, et al. Genetically modified human derived bone marrow cells for posterolateral lumbar spine fusion in athymic rats: beyond conventional autologous bone grafting. Spine (Phila $\mathrm{Pa} 1976)$ 2005;30:283-9; discussion 289-90.

124. Nakashima M, Reddi AH. The application of bone morphogenetic proteins to dental tissue engineering. Nat Biotechnol 2003;21:1025-32.

125. Requicha JF, Viegas CA, Albuquerque CM, et al. Effect of anatomical origin and cell passage number on the stemness and osteogenic differentiation potential of canine adiposederived stem cells. Stem Cell Rev Rep 2012;8:1211-22.

126. Bougioukli S, Sugiyama O, Pannell W, et al. Gene Therapy for Bone Repair Using Human Cells: Superior Osteogenic Potential of Bone Morphogenetic Protein 2-Transduced Mesenchymal Stem Cells Derived from Adipose Tissue Compared to Bone Marrow. Hum Gene Ther 2018;29:507-19.

127. Hirata K, Tsukazaki T, Kadowaki A, et al. Transplantation 
of skin fibroblasts expressing BMP-2 promotes bone repair more effectively than those expressing Runx2. Bone 2003;32:502-12.

128. Keeney M, Chung MT, Zielins ER, et al. Scaffoldmediated BMP-2 minicircle DNA delivery accelerated bone repair in a mouse critical-size calvarial defect model. J Biomed Mater Res A 2016;104:2099-107.

129. Shin JH, Kim KH, Kim SH, et al. Ex vivo bone morphogenetic protein-2 gene delivery using gingival fibroblasts promotes bone regeneration in rats. J Clin Periodontol 2010;37:305-11.

130. Worgall S, Crystal RG. Gene Therapy. In: Principles of Tissue Engineering Elsevier, 2014:657-86.

131. Kofron MD, Laurencin CT. Bone tissue engineering by gene delivery. Adv Drug Deliv Rev 2006;58:555-76.

132. Nayak S, Herzog RW. Progress and prospects: immune responses to viral vectors. Gene Ther 2010;17:295-304.

133. Somia N, Verma IM. Gene therapy: trials and tribulations.

doi: 10.21037/fomm-21-9

Cite this article as: Khazaal H, Helman J. Narrative review: craniofacial bone regeneration-where are we now? Front Oral Maxillofac Med 2022;4:9.
Nat Rev Genet 2000;1:91-9.

134. Kaiser J. Gene therapy. Seeking the cause of induced leukemias in X-SCID trial. Science 2003;299:495.

135.He X, Dziak R, Yuan X, et al. BMP2 genetically engineered MSCs and EPCs promote vascularized bone regeneration in rat critical-sized calvarial bone defects. PLoS One 2013;8:e60473.

136. Lin CY, Chang YH, Kao CY, et al. Augmented healing of critical-size calvarial defects by baculovirusengineered MSCs that persistently express growth factors. Biomaterials 2012;33:3682-92.

137. Kichler A, Leborgne C, Coeytaux E, et al. Polyethylenimine-mediated gene delivery: a mechanistic study. J Gene Med 2001;3:135-44.

138. Kolk A, Tischer T, Koch C, et al. A novel nonviral gene delivery tool of BMP-2 for the reconstitution of critical-size bone defects in rats. J Biomed Mater Res A 2016;104:2441-55. 